\title{
THE INFLUENCE OF RISK AND PROTECTIVE FACTORS ON TOBACCO, ALCOHOL AND DRUGS IN ADOLESCENCE
}

\author{
Mafalda Ferreira, Margarida Gaspar de Matos, José Alves Diniz \\ Technical University of Lisbon, Cruz Quebrada, Portugal \\ E-mail: fafi@sapo.pt, mmatos@fmh.utl.pt, jadiniz@fmh.utl.pt
}

\begin{abstract}
The purpose of this study is to analyse the relation between risk and protective factor and substance use in adolescence, including tobacco use, drunkenness and consumption of illicit drugs.

The sample included 3494 students, mean age 15 years old, in the $8^{\text {th }}$ and $10^{\text {th }}$ grades from the public school system, of primary and secondary schools in Portugal. Data collection was held within the HBSC (Health Behavior in School-aged Children) survey from 2010. For the purpose of this specific study, the questionnaire includes questions about risk and protective behaviors and substance use, namely tobacco, drunkenness and illicit drug consumption.

Results confirmed that adolescents with higher levels of protective factors seem to consume fewer substances and adolescents who present higher levels of risk factors are more likely to consume all the substances in the study. There were statistically significant differences for the majority of risk and protective behaviours regarding tobacco, drunkenness and illicit drugs. Although risk factors have a higher impact on substance use, the existence of protective factors seems to fade such impact.
\end{abstract}

Key words: adolescence, risk and protective factors, substance use.

\section{Introduction}

Adolescence is a transitional period of psychological, physical and contextual variations and risk-taking. Risk behaviors that include substance use in adolescence, such as tobacco, alcohol and illicit drugs, are some of the most concerning risk behaviors.

Smoking rates among adolescents have been growing over the last decade in some countries (WHO, 2009). The most recent Portuguese statistics show that $15.6 \%$ of students from the $8^{\text {th }}$ and $10^{\text {th }}$ grades reported smoking at least once a week; though the majority of students reported not smoking at all (Matos et al, 2011). The World Health Organization (2011) enhances alcohol consumption as one of the major risk factors on health problems that represent a public health issue to society. In Portugal, according to the data of national HBSC (2010), $32 \%$ of students from the $8^{\text {th }}$ and $10^{\text {th }}$ grades have been drunk once or more times in their life (Matos et al, 2011). Finally, the harmful use of illicit drugs is also recognized as a major public health problem throughout the world, and research on the long-term effects of chronic marijuana use shows association to cognitive functioning and respiratory problems (WHO, 2009). In Portugal, regarding illicit drug use in the last 30 days, 7.5\% of students from the $8^{\text {th }}$ and $10^{\text {th }}$ grades reported using it once or more times, according to the same HBSC data (Matos et al., 2011). 
Over the years, several research studies highlight the association between risk and protective factors and substance use in adolescence (Stone, Becker, Huber \& Catalano, 2012).

Risk factors associated with adolescents' varied social contexts are related to increased substance use and abuse (Kliewer \& Murrelle, 2007), and this behavior seems to be linked not only to the availability of the substance, the perceived safety and to substance tolerance, but also to a large number of risk factors that increase the vulnerability to substance use. Among the risk behaviors associated to a higher intake of substances in adolescence, for the ones relevant to the purpose of this study are: (1) Low school bonding; adolescents who have a low commitment to school or miss classes are more likely to become substance involved (Birckmayer et al., 2004); (2) Peers engaging in problem behaviors; adolescents who spend a large number of nights with their peers during school nights have higher rates of substance use (Van Ryzin, Fosco \& Dishion, 2012; Matos, 2009); and (3) Violence involvement; the association between externalizing behaviors as aggression (Engels et al., 2005) antisocial or conduct problems (Bor, McGee, Hayatbakhsh, Dean \&Najman, 2010) and violence is well-known.

On the other hand, protective factors have also been identified as predictors of lower rates of substance use in adolescence. According to several research studies, protective factors can increase the resistance to problem behavior and inhibit its development. Therefore, the present study considered the following protective factors: (1) Parental Monitoring; family is a developing and socializing context were children learn and internalize values and norms, and good parental monitoring is associated with better school adjustment, less antisocial and delinquent activities and lower substance use (Van Ryzin \& Dishion, 2012); (2) Satisfaction with the global family atmosphere; adolescents who report a better relationship with parents are also less involved in risk behaviors, such as substance use (Hartup, 2006); (3) Personal resilience; internal assets are closely related with global well-being, adolescents who present higher levels of resilience and emotional and social skills are more likely to be involved in protective behaviors (Ferreira, et al., 2012); (4) Relationships with peers; in adolescence peers become crucial to the personal development and identity definition . Some studies enhance the importance of having friends for a healthy lifestyle and that the lack of friends is related to higher rates of substance use (Tomé et al., 2008).

The aim of this study is: (1) to analyze the relation between risk and protective factors and tobacco consumption; (2) to analyze the relation between risk and protective factors and drunkenness; and (3) to analyze the relation between risk and protective factors and illicit drug use in the last thirty days.

\section{Methodology of Research}

\section{General Background of Research}

Data was collected through a self-administered questionnaire from the Portuguese study of the Health Behavior in School-aged Children (HBSC) of 2010, a World Health Organization (WHO) collaborative cross-national study (Currie, Roberts, Morgan, \& Smith, 2004; Matos et al., 2011).

\section{Sample of Research}

The study provides nationally representative data of 3494 Portuguese adolescents, randomly selected from those attending $8^{\text {th }}$ and $10^{\text {th }}$ grades. The majority of adolescents has Portuguese nationality $(94.2 \%), 46.4 \%$ are boys and $53.6 \%$ are girls. The students were proportionally distributed among six educational Portuguese regions. More than half of the adolescents have a low socioeconomic status $(55.9 \%)$. 


\section{Instrument and Procedures}

The HBSC is a school-based survey of adolescent health behaviors and their psychosocial determinants, carried out every 4 years simultaneously in all participating countries, using an international standardized methodological protocol (Currie, Roberts, Morgan, \& Smith, 2004; Currie, Samdal, Boyce, \& Smith, 2001). The HBSC study includes school children aged 11,13 and $15\left(6^{\text {th }}\right.$, $8^{\text {th }}$ and $10^{\text {th }}$ grade students) in 44 countries in Europe and North America. According to the study protocol, data from each country is gathered from nationally representative samples. The HBSC uses a standard, self-administered in-class questionnaire that includes both mandatory and optional items. A detailed description of the methods and instrument of the HBSC can be found in Currie et al (Currie, Molcho, Boyce, Holstein, \& Torsheim, 2008; Currie, Roberts, Morgan, \& Smith, 2004). This Nationwide Survey was conducted during 2009/2010 academic year and the sampling unit used was the class. The 139 schools in the sample were randomly selected from the official national list of public schools, stratified by region. In each school, classes were randomly selected for each grade, according to the international research protocol (Currie, Roberts, Morgan, \& Smith, 2004). The application of the questionnaire was carried by school teachers. This study had the approval of a scientific committee, the National Ethics Committee and the National Commission for Data Protection and followed strictly all the guidelines for human rights protection.

The international standard questionnaire consists of three levels of questions which are used to create national survey instruments: core questions that each country is required to include to create the international dataset; optional packages of questions on specific topic areas from which countries can choose; and country-specific questions related to issues of national importance.

Survey questions cover a range of health indicators and health-related behaviors as well as the life circumstances of young people. Questions are subject to validation studies and piloting at national and international levels. The core questions provide information on: demographic factors (e. g., gender, age and state of maturation); social background (e. g., family structure and socioeconomic status); social context (e. g., family, peer culture, school environment); health outcomes (e. g., selfrated health, injuries, overweight and obesity); health behaviors (e. g., eating and dieting, physical activity and weight reduction behavior); and risk behaviors (e. g., smoking, alcohol use, cannabis use, sexual behavior, bullying). For the purpose of this study, the following questions were used:

Table 1. Questions about risk and protective behaviors, and substance use, used in the present study.

\begin{tabular}{|c|c|c|}
\hline & Items & Responses \\
\hline Risk behaviour: violence & $\begin{array}{l}\text { During the past } 12 \text { months, how many times } \\
\text { were you in a physical fight? }\end{array}$ & $\begin{array}{l}\text { 1. I have not } \\
\text { 2. } 1 \text { time } \\
\text { 3. } 2 \text { times } \\
\text { 4. } 3 \text { times } \\
\text { 5. } 4 \text { times or more }\end{array}$ \\
\hline Risk behaviour: carry weapon & $\begin{array}{l}\text { During the past } 30 \text { th days, on how many days } \\
\text { did you carry a weapon, such as a gun, knife } \\
\text { or club? }\end{array}$ & $\begin{array}{l}\text { 1. I did not carry a weapon during } \\
\text { the past } 30 \text { days } \\
\text { 2. } 1 \text { day } \\
\text { 3. } 2 \text { to } 3 \text { days } \\
\text { 4. } 4 \text { to } 5 \text { days } \\
\text { 5. } 6 \text { or more days }\end{array}$ \\
\hline $\begin{array}{l}\text { Risk behaviour: school } \\
\text { engagement }\end{array}$ & It happens missing classes: & $\begin{array}{ll}\text { 1. } & \text { Never } \\
\text { 2. } & \text { Sometimes } \\
\text { 3. I miss a lot } \\
\text { 4. At present, hardly go to school }\end{array}$ \\
\hline $\begin{array}{l}\text { Risk behaviour: nights with } \\
\text { friends }\end{array}$ & $\begin{array}{l}\text { How many nights per week do you usually } \\
\text { spend out with your friends? }\end{array}$ & $\begin{array}{l}0 . \quad 0 \text { nights } \\
\text { To } \\
\text { 8. } 7 \text { nights }\end{array}$ \\
\hline
\end{tabular}




\begin{tabular}{|c|c|c|}
\hline $\begin{array}{l}\text { Protective behaviour: } \\
\text { Parental Monitoring Scale }\end{array}$ & $\begin{array}{l}\text { How much did your parents really know about: } \\
\text { Who are your friends? } \\
\text { How do you spend your money? } \\
\text { Where are you after school? } \\
\text { Where are you going night out? } \\
\text { What do you do with your free time? }\end{array}$ & $\begin{array}{l}\text { 1. Don't know nothing } \\
\text { 2. Know a little } \\
\text { 3. Know a lot }\end{array}$ \\
\hline $\begin{array}{l}\text { Protective behaviour: } \\
\text { Satisfaction with the global } \\
\text { family atmosphere scale }\end{array}$ & $\begin{array}{l}\text { In general, how satisfied are you with the } \\
\text { relationship in your family? }\end{array}$ & $\begin{array}{l}\text { 0. We have very bad relationships } \\
\text { in our family; } \\
\text { To } \\
\text { 10. We have very good relationships } \\
\text { in our family. }\end{array}$ \\
\hline $\begin{array}{l}\text { Protective behaviour: } \\
\text { Resilience scale }\end{array}$ & $\begin{array}{l}\text { When I'm learning something new, if I cannot, I } \\
\text { give up easily. } \\
\text { When I make plans, I am confident that I can } \\
\text { perform them. } \\
\text { When I cannot do things at first, I insist and } \\
\text { keep trying until I get it done. }\end{array}$ & $\begin{array}{ll}\text { 1. } & \text { 1. Never } \\
\text { 2. } & \text { 2. Rarely } \\
\text { 3. } & \text { 3. Sometimes } \\
\text { 4. } & \text { 4. A lot of the times } \\
\text { 5. } & \text { 5. Ever }\end{array}$ \\
\hline $\begin{array}{l}\text { Protective behaviour: } \\
\text { Making friends }\end{array}$ & For you, is it easy or difficult make new friends? & $\begin{array}{ll}\text { 1. } & \text { Very difficult } \\
\text { 2. } & \text { Difficult } \\
\text { 3. } & \text { Easy } \\
\text { 4. } & \text { Very easy }\end{array}$ \\
\hline Substance use: tobacco & How often do you smoke? & $\begin{array}{l}\text { 1. I do not smoke } \\
\text { 2. Less than once a week } \\
\text { 3. At least once a week, but not } \\
\text { every day } \\
\text { 4. Every day }\end{array}$ \\
\hline Substance use: drunkenness & Have you ever been drunk? & $\begin{array}{ll}\text { 1. } & \text { No, never } \\
\text { 2. } & \text { Yes, once } \\
\text { 3. } & \text { Yes, } 2-3 \text { times } \\
\text { 4. } & \text { Yes, } 4-10 \text { times } \\
\text { 5. } & \text { Yes, more than } 10 \text { times }\end{array}$ \\
\hline Substance use: illicit drugs & $\begin{array}{l}\text { How often did you use illicit drugs in the last } \\
\text { month? }\end{array}$ & $\begin{array}{ll}\text { 1. None } \\
\text { 2. Once } \\
\text { 3. More than once } \\
\text { 4. Often }\end{array}$ \\
\hline
\end{tabular}

\section{Data Analysis}

The data were analysed using the Statistical Package for Social Sciences (SPSS) version 19. Reliability analysis was conducted with items from two subscales and both shown to have accepted reliability, namely parental monitoring with 5 items (Cronbach's alpha of 0.83 ) and resilience with 3 items (Cronbach's alpha of 0.65). Regarding the regression analysis, all variables were converted into Z scores, except "parental monitoring" and "resilience" scales. All significant results were discussed.

\section{Results of Research}

The multiple linear regression analysis was performed to examine the predictors of consumption and abuse of tobacco, alcohol use (drunkenness) and illicit drugs use in the last month. Concerning tobacco consumption, a multiple linear regression model with four protective behaviour preditor variables: parental monitoring scale, satisfaction with family, resilience scale and making friends showed to be adjusted $(\mathrm{F}(4,2756)=39.518, p \leq 0.001)$ and the regression equation explained $5.3 \%$. In a second block, when added four predictor variables of risk behaviour, the model explained $16.6 \%$, also an adjusted model $(\mathrm{F}(8,2752)=69.787, p \leq 0.001)($ Table 2$)$. 
ISSN 2029-8587

PROBLEMS

OF PSYCHOLOGY

IN THE $21^{\text {st }}$ CENTURY Volume 6, 2013

Table 2. Multiple linear regression for tobacco consumption.

\begin{tabular}{cccccc}
\hline Variable & Variable included & $\boldsymbol{\beta}$ & $\mathrm{t}$ & $\mathbf{p}$ & Adj R2 \\
\hline \multirow{3}{*}{$\begin{array}{c}\text { Tobacco consumption } \\
\text { Model 1 }\end{array}$} & Parental monitoring & -0.142 & -7.082 & 0.000 & \\
& Satisfaction with family & -0.062 & -5.894 & 0.000 & 0.053 \\
& Resilience & -0.050 & -2.519 & 0.012 & \\
& Making friends & 0.115 & 5.793 & 0.000 & \\
& Parental monitoring & -0.083 & -4.346 & 0.000 & \\
& Satisfaction with family & -0.055 & -5.552 & 0.000 & \\
Tobacco consumption & Resilience & -0.028 & -1.489 & 0.136 & \\
Model 2 & Making friends & 0.068 & 3.610 & 0.000 & \\
& Violence & 0.082 & 4.104 & 0.000 & 0.166 \\
& Carry weapon & 0.019 & 1.102 & 0.271 & \\
& School engagement & 0.117 & 6.200 & 0.000 & \\
& Nights with friends & 0.284 & 14.884 & 0.000 & \\
& & & & &
\end{tabular}

Concerning drunkenness, a multiple linear regression model was explained by three of the four protective behaviours predicting variables: parental monitoring scale, satisfaction with family and making friends resulted in an adjusted model $(\mathrm{F}(4,2776)=28.535, p \leq 0.001)$ and the regression equation explained $3.8 \%$. In a second block, after adding four predictor variables of risk behaviour, three of them, namely violence, school engagement and spend nights with friends, were also significant $(\mathrm{F}(8,2772)=83.935, p \leq 0.001)$ and the regression equation explained $19.3 \%$ (Table 3 ).

Table 3. Multiple linear regression for drunkenness.

\begin{tabular}{cccccc}
\hline Variable & Variable included & $\boldsymbol{\beta}$ & $\mathbf{t}$ & $\mathbf{p}$ & Adj R2 \\
\hline & Parental monitoring & -0.117 & -5.975 & 0.000 & 0.038 \\
Drunkenness & Satisfaction with family & -0.048 & -4.631 & 0.000 & 0.058 \\
Model 1 & Resilience & -0.037 & -1.893 & 0.000 \\
\hline Making friends & 0.117 & 5.930 & -2.991 & 0.003 \\
Drunkenness & Parental monitoring & -0.055 & -4.309 & 0.000 \\
Model 2 & Satisfaction with family & -0.041 & -0.784 & 0.433 \\
& Resilience & -0.014 & 3.310 & 0.001 & 0.193 \\
& Making friends & 0.060 & 6.033 & 0.000 \\
& Violence & 0.116 & 1.815 & 0.070 \\
& Carry weapon & 0.031 & 5.325 & 0.000
\end{tabular}

Concerning illicit drug use in the last month, also a multiple linear regression model is explained by all of the four protective behaviours predicting variables: parental monitoring scale, satisfaction with family, resilience and making friends, resulting in an adjusted model $(\mathrm{F}(4,2588)=$ $25.825, p \leq 0.001)$ and the regression equation explaining 3.7\%. In a second block, after adding four predictor variables of risk behaviours, the model explained $18.9 \%$ and showed to be adjusted ( $\mathrm{F}(8$, $2584)=76.340, p \leq 0.001)($ Table 4$)$. 
Table 4. Multiple linear regression for illicit drugs use.

\begin{tabular}{|c|c|c|c|c|c|}
\hline Variable & Variable included & $\beta$ & $t$ & $p$ & Adj R2 \\
\hline \multirow{4}{*}{$\begin{array}{l}\text { Illicit drugs use } \\
\text { Model } 1\end{array}$} & Parental monitoring & -0.134 & -5.943 & 0.000 & \multirow{4}{*}{0.037} \\
\hline & Satisfaction with family & -0.054 & -4.531 & 0.000 & \\
\hline & Resilience & -0.059 & -2.575 & 0.010 & \\
\hline & Making friends & 0.091 & 4.018 & 0.000 & \\
\hline \multirow{8}{*}{$\begin{array}{l}\text { Illicit drugs use } \\
\text { Model } 2\end{array}$} & Parental monitoring & -0.051 & -2.419 & 0.016 & \multirow{8}{*}{0.189} \\
\hline & Satisfaction with family & -0.034 & -3.081 & 0.002 & \\
\hline & Resilience & -0.027 & -1.285 & 0.199 & \\
\hline & Making friends & 0.053 & 2.507 & 0.012 & \\
\hline & Violence & 0.068 & 3.065 & 0.002 & \\
\hline & Carry weapon & 0.217 & 11.039 & 0.000 & \\
\hline & School engagement & 0.261 & 12.277 & 0.000 & \\
\hline & Nights with friends & 0.128 & 6.024 & 0.000 & \\
\hline
\end{tabular}

Although the majority of students in the sample don't smoke (84.4\%), never got drunk (68\%) and never used illicit drugs in the last month (92.5\%) the students who report these behaviors have other risk behaviors associated. Analyzing the differences between risk and protective factors, we verified that risk factors strongly explain substance use. However, the variables related with family showed to be a good predictor and a protective factor regarding substance use. These variables remained significant predictors even when risk behaviors were added, and also contribute for the global explanation. Such was not true for personal factors, such as resilience.

Although ease in making friends was first included in the first block (protective factor) in the assumption of its importance in adolescent well-being, the variable was, however, positively associated with all substance use, and therefore considered a risk factor.

\section{Discussion}

In the present study was intended to establish a relation between risk and protective factors and substance use in adolescence, including tobacco consumption, frequency of drunkenness and consumption of illicit drugs in the last month.

Results showed that adolescents that refer no substance consumption present higher levels of protective factors, but more important, less associated risk factors. For smoking, the significant differences found were on violence, school engagement, nights spent with friends, and making friends with a positive association; parental monitoring and satisfaction with family appear in the opposite side, suggesting a positive relation to the importance of parental support and monitoring, as reported in the literature on this topic (Wu, Chong, Cheng \& Chen, 2012; Hummel et al., 2012; Ikiz \& Cakar, 2010).

Regarding alcohol consumption, there were no significant differences for the resilience scale and carry a weapon. Although the same pattern as tobacco consumption was verified for the other predictors in the study. These results support the hypothesis that prevention needs to be consistent with each substance, whilst also showing the similarity in substances such as tobacco and alcohol, in terms of intervention (Johnston, O'Malley, Bachman \& Schulenberg, 2008).

Concerning illicit drugs, we can clearly verify that the adolescents that refer using illicit drugs in the last month present higher levels of all the risk factors in the study.

Nevertheless, the overall explanation of the different models didn't seem stronger, therefore it is important to analyse the influence that risk factors have in substance use, because for all substances in study we can verified that risk and protective factors together can explain four times more than protective factors alone. Some hypotheses can be raised to understand these results. The school context (peer group) and social environment in which the adolescent is integrated has been identified as the 
most consistent predictor of substance use in adolescence (Kuntsche \& Jordan, 2006), highlighting the need to explore the behaviors associated with these specific contexts. Capaldi et al (2009) argues that while parents are most influential during childhood, peers have the strongest influence on problem behaviours during adolescence. However, according to the authors, parental monitoring at this age and their efforts at reducing the opportunities for their child to engage in drinking with their peers is still one of the most important prevention strategies.

In addition, a positive family environment acts as a protection mechanism against negative peer influences, while poor satisfaction with family amplifies the negative peer effects, as we can see by the results. These are crucial in order to enhance the prevention of behaviors that are harmful to one's health (Filho \& Ferreira-Borges, 2008; Bachman, et al, 2008).

\section{Conclusions}

Although it is important to understand the whole system of contexts in which adolescents are involved, it is also important to rethink strategies to combat the current figures related to substance use (Hibell, 2009). The HBSC study aims to inform and have impact on policies for promotion and health education, and programs and interventions for adolescents, nationally and internationally, providing a valid set of indicators as a representation of adolescents' health and lifestyles (Hublet, et al, 2009).

The results of this research suggest that policies regarding substance use in adolescence should direct their attention towards youngsters who are more peer-oriented and are frequently going out at night. Policies should focus on the social and psychological processes in friendship groups that encourage substance use among its members. Furthermore, parental monitoring and satisfaction within family could be an effective strategy in preventing excessive substance use patterns.

Adolescents explore and experiment different life styles and typical adult behaviours for various reasons, mainly to promote independence from parents and develop an individual identity. However, young people are not truly able to make rational decisions until the maturation of the brain (around the age of 23-25). Therefore, it is crucial to understand protective contexts, such as family, peers and school, setting human free choice as a central topic of discussion, where health professionals and educators, should offer adolescents an opportunity to think and talk about their choices. More than considering risk behaviour as dangerous for itself, it is important to keep a dialogue with youths, and education concerning risky behaviour can help them proceed toward adulthood in the healthier way possible.

According to several studies, besides the presence of personal characteristics, parental and peer relationships as critical factors to predict substance use in adolescence, it is also crucial to look at the importance of the level of risk and protective factors in order to establish a program for health promotion in adolescence, contributing for higher indicators of well-being.

A few limitations must be addressed regarding this study. The first concerns the self-report nature of the surveys. Self-reported data depends on selective memory and therefore findings may be biased.

The second limitation is the cross-sectional nature of the study, which does not allow causality assumption. Also considering this specific topic, social desirability effect can be expected and therefore results may be underestimated for substance users. Finally, this study used measures designed for a broad national survey. The post-hoc nature of the variables is also a limitation.

\section{Acknowledgements}

Thank you to the Aventura Social Project Team for their fieldwork, and data collection. The first author has a scholarship granted by FCT - (SFRH/BD/45671/2008)/FMH/UTL/CMDT-UNL.

\section{References}

Bachman, J. G., O’Malley, P. M., Schulenberg, J. E., Johnston, L. D., Freedman, P., \& Messerschmith, E. E. (2008). The education-drug use connection. How successes and failures in school relate to adolescent smoking, drinking, drug use, and delinquency. New York, Lawrence Erlbaum Associates. 
Birckmayer, J. D., Holder, H. D., Yacoubian, G. S., \& Friend, K. B. (2004). A general causal model to guide alcohol, tobacco, and illicit drug prevention: Assessing the research evidence. Journal of Drug Education, 34 (2), 121-153.

Bor, W., McGee, T.R., Hayatbakhsh, M. R., Najman, J. M., \& Dean, A. (2010). Do antisocial females exhibit poor outcomes in adulthood? An Australian cohort study. Australian and New Zealand Journal of Psychiatry, 44, 7, 648-657.

Capaldi, D. M., Stoolmiller, M., Kim, H. K., \& Yoerger, K. (2009). Growth in alcohol use in at-risk adolescent boys: Two-part random effects prediction models. Journal of Drug and Alcohol Dependence, 105, 109-117.

Currie, C., Molcho, M., Boyce, W., Holstein, B., \& Torsheim, T. (2008). Researching health inequalities in adolescents: the development of the health behaviour in school-aged children (HBSC) family affluence scale. Social Science \& Medicine, 66 (6), 1429-1436.

Currie, C., Roberts, C., Morgan, A., \& Smith, R. (2004). Young people's health in context: international report from the HBSC 2001/02 survey. In WHO policy series: Health policy for children and adolescents. Copenhagen: WHO regional office for Europe.

Currie, C., Samdal, O., Boyce, W., \& Smith, B. (2001). Health behaviour in school-aged children: AWHO cross-national study. A research protocol for the 2001/2 survey. Edinburgh, Scotland: Child and Adolescent Health Research Unit (CAHRU), University of Edinburgh.

Engels, R., Vermult, A., Dubas, J., Bot, S., \& Gerris, J. (2005). Long-term Effects of Family Functioning and Child Characteristics on Problem Drinking in Young Adulthood. European Addiction Research, 11 (1), 32-37.

Faggiano, F., Vigna-Taglianti, F., Versino, E., Zambon, A., Borraccino, A., \& Lemma, P. (2005). School-based prevention for illicit drugs' use. Cochrane Database of Systematic Reviews 2005, Issue 2. Art. No.: CD003020. DOI: 10.1002/14651858.CD003020.pub2

Ferreira, M., Simões, C., Matos, M. G., Ramiro, L., \& Diniz, J. A. (2012). The role of social and emotional competence on risk behaviors in adolescence. The International Journal of Emotional Education, 4 (1), 43-55.

Filho, H. C., \& Ferreira-Borges, C. (2008). Uso de Substâncias: Álcool, Tabaco e outras Drogas. Lisboa: Coisas de Ler.

Fothergill, K. E., \& Ensminger, M. E. (2006). Childhood and adolescent antecedents of drug and alcohol problems: A longitudinal study. Drug and Alcohol Dependence, 82 (1), 61-76.

Hartup, W. (2005). Peer interaction: What causes what? Journal of Abnormal Child Psychology, 3, 387-394.

Hibell, B., Guttormsson, U., Ahlström, S., Balakireva, O., Bjarnason, T., Kokkevi, A., \& Kraus, L. (2009). The 2007 ESPAD Report - Substance Use Among Students in 35 European Countries. The Swedish Council for Information on Alcohol and Other Drugs (CAN), Stockholm.

Hublet, A., Schmid, H., Clays, E., Godeau, E., NicGabhainn, S., Joossens, L., \& Maes, L. (2009). Association between tobacco control policies and smoking behaviour among adolescents in 29 European countries. Addiction, 104 (11), 1918-26. doi: 10.1111/j.1360-0443.2009.02686.x.

Hummel, A., Shelton, K. H., Heron, J., van den Moore, L., \& Bree, M. B. (2012). A systematic review of the relationships between family functioning, pubertal timing and adolescent substance use. Addiction, 108 (3), 487-96. doi: 10.1111/add.12055.

Ikiz, F. E., \& Cakar, F. S. (2010). Perceived social support and self-esteem in adolescence. Procedia-Social and Behavioral Sciences, 5, 2338-2342.

Johnston, L. D., O’Malley, P. M., Bachman, J. G., \& Schulenberg, J. E. (2008). Monitoring the future: National results on adolescent drug use. Overview of key findings, 2008. Bethesda, MD: National Institute on Drug Abuse.

Kliewer, W., \& Murrelle, L. (2007). Risk and protective factors for adolescent substance use: Findings from a study in selected Central American countries. Journal of Adolescent Health, 40, 448-455.

Kuntsche, E., \& Jordan, M. D. (2006). Adolescent alcohol and cannabis use in relation to peer and school factors: Results of multilevel analyses. Drug and Alcohol Dependence, 84, 167-174.

Matos, M. G., \& Sampaio, D. (Eds.). (2009). Jovens com Saúde: Diálogo com uma geração. Lisboa: Texto.

Matos, M.G., Simões, C., Tomé, G., Camacho, I., Ferreira, M., Ramiro, L., Reis, M., \& equipa Aventura Social 
ISSN 2029-8587

PROBLEMS

OF PSYCHOLOGY

IN THE $21^{\text {st }}$ CENTURY Volume 6, 2013

14

(2011). A Saúde dos Adolescentes Portugueses - Relatório do Estudo HBSC 2010. ACS/FMH/UTL/ CMDT-UNL.

Schenker, M., \& Minayo, M. (2005). Factores de risco e de protecção para o uso de drogas na adolescência. Ciência \& Saúde Coletiva, 10,707-717.

Simões, C. (2007). Comportamentos de risco na adolescência. Lisboa: Fundação Calouste Gulbenkian/Fundação para a Ciência e Tecnologia.

Stone, A. L., Becker, L. G., Huber, A. M., \& Catalano, R. F. (2012). Review of risk and protective factors of substance use and problem use in emerging adulthood. Addictive Behaviour, 37 (7), 747-75. doi: 10.1016/j.addbeh.2012.02.014.

Tomé, G., Matos, M., \& Diniz, A. (2008). Consumo de substâncias e isolamento social durante a adolescência. In M. Matos (Ed.), Consumo de substâncias: Estilo de vida? À procura de um estilo? (pp. 95-126). Lisboa, Portugal: Instituto da Droga e da Toxicodependência.

Van Ryzin, M. J., Fosco, G. M., \& Dishion, T. J. (2012). Family and peer predictors of substance use from early adolescence to early adulthood: an 11-year prospective analysis. Addictive Behaviour, 37 (12), 1314-24. doi: 10.1016/j.addbeh.2012.06.020

Van Ryzin, M. J., \& Dishion, T. J. (2012). The impact of a family-centered intervention on the ecology of adolescent antisocial behavior: modeling developmental sequelae and trajectories during adolescence. Development and Psychopathology, 24 (3), 1139-55. doi: 10.1017/S0954579412000582.

Windle, M. (2003). Alcohol use among adolescents and young adults. Alcohol Research and Health, 27 (1), 79-86.

World Health Organization (WHO) (Ed.). (2002). The world health report 2002 - Reducing risks, promoting healthy life. Geneva: World Health Organization (WHO).

World Health Organization (WHO). (2009). WHO report on the global tobacco epidemic, 2009: implementing smoke-free environments. Geneva: World Health Organization (WHO).

World Health Organization (WHO) (Ed.). (2011). Global status report on alcohol and health. Geneva: World Health Organization (WHO).

Wu, G. H., Chong, M. Y., Cheng, A. T., \& Chen, T. H. (2012). Correlates of family, school, and peer variables with adolescent substance use in Taiwan. Social Science \& Medicine, 64 (12), 2594-600.

Advised by Vincentas Lamanauskas, University of Šiauliai, Lithuania

Received: April 02, 2013

Accepted: June 05, 2013

\begin{tabular}{|c|c|}
\hline Mafalda Ferreira & $\begin{array}{l}\text { PhD, Health Psychologist, Technical University of Lisbon (UTL), CMDT \& Aventura Social } \\
\text { Project, Estrada da Costa - Cruz Quebrada, Portugal. } \\
\text { E-mail: fafi@sapo.pt } \\
\text { Website: www.aventurasocial.com }\end{array}$ \\
\hline $\begin{array}{r}\text { Margarida Gaspar de } \\
\text { Matos }\end{array}$ & $\begin{array}{l}\text { PhD, Full Professor, Clinical and Health Psychologist, Technical University of Lisbon (UTL), } \\
\text { CMDT \& Aventura Social Project, Estrada da Costa - Cruz Quebrada, Portugal. } \\
\text { E-mail: mmatos@fmh.utl.pt } \\
\text { Website: www.aventurasocial.com }\end{array}$ \\
\hline José Alves Diniz & $\begin{array}{l}\text { PhD, Professor, Technical University of Lisbon (UTL), Aventura Social Project, Estrada da } \\
\text { Costa - Cruz Quebrada, Portugal. } \\
\text { E-mail: jadiniz@fmh.utl.pt.com } \\
\text { Website: www.aventurasocial.com }\end{array}$ \\
\hline
\end{tabular}

